\title{
Direct Analysis of Carbon Isotope Variability in Albumins by Liquid Flow-Injection Isotope Ratio Mass Spectrometry
}

\author{
Richard J. Caimi and J. Thomas Brenna \\ Division of Nutritional Sciences, Cornell University, Ithaca, New York, USA
}

\begin{abstract}
We demonstrate the high precision $C$ isotopic analysis of a series of purified albumins by liquid chromatography-combustion isotope ratio mass spectrometry (IRMS) by using direct aqueous liquid injection. Albumins from 18 species and albumens from chicken and turkey egg were obtained from a commercial source and shown to be of $>98 \%$ purity by capillary zone electrophoresis and high-performance liquid chromatography. One microliter of an aqueous protein solution with a total of $<40$-pmol protein $(2.5 \mu \mathrm{g})$, which contained about 150 -nmol C, was injected directly into a flowing stream of high-performance liquid chromatography grade water. The solution passed through a pneumatic nebulizer, was sprayed onto a moving wire, passed through a drying oven, and was combusted in a furnace. After the water of combustion was removed, the resulting $\mathrm{CO}_{2}$ gas was directed to a high precision IRMS instrument operated in continuous flow mode. The average precision across the 20 samples analyzed was $\operatorname{SD}\left(\delta^{13} \mathrm{C}\right)=0.45 \%$, and the average accuracy was $\delta^{13} \mathrm{C}<$ $0.4 \%$ compared to aliquots analyzed by conventional preparation by using combustion tubes and dual inlet analysis. The ubserved isotope ratio range was about $-22.5 \%<$ $\delta^{13} \mathrm{C}_{\mathrm{PDB}}<-16 \%$ as expected for modern materials from a natural source. These results demonstrate rapid, high precision, and accurate $C$ isotopic analysis of untreated macromolecules in an aqueous stream by liquid source IRMS. (J Am Soc Mass Spectrom 1996, 7, $605-610$ )
\end{abstract}

$\mathrm{H}$ igh precision gas isolope ratio mass spectrometry (IRMS) has been used extensively for several decades for the isotopic analysis of the light elements $\mathrm{C}, \mathrm{H}, \mathrm{N}, \mathrm{O}$, and S [1]. Conventional high precision analysis is accomplished by admitting samples in the form of light stable gases into these instruments through the classical dual inlet interface. However, this approach is limited by the large sample size requirements dictated by the practicalities of viscous gas flow [2]. Subsequent development of continuous flow (CF) and gas chromatography combustion isotope ratio mass spectrometry (GCC-IRMS) techniques have reduced sample size requirements by several orders of magnitude and have facilitated compound specific isotope analyses (CSIA) in which isotope ratios are derived for individual components of complex mixtures [3-6]. The primary limitations of these inlet systems stem from their requirement for gas-phase analyte, which imposes demands for volatility and thermal stability. The vast majority of biologically interesting molecules cannot satisfy one or both of these requirements in their natural state.

Address reprint requests to Dr. J. T. Brenna, Cornell University, Savage Hall, Ithaca, NY 14853.
In 1993, we introduced a CF interface that allows the analysis of nonvolatile and thermally labile molecules [7]. Referred to as liquid chromatographycombustion-isotope ratio mass spectrometry (LCCIRMS), this interface facilitated for the first time on-line coupling of liquid chromatography with IRMS through the use of a mechanical transport. Briefly, analyte molecules in solvent are coated onto a moving transport and, by using a drying oven and a combustion furnace, solvent is removed reproducibly and organic analyte molecules are converted quantitatively to $\mathrm{CO}_{2}$ and water. The $\mathrm{CO}_{2}$ is then dried and admitted into the ion source of a high precision IRMS instrument for isotope ratio analysis.

The interface is operated in two different modes: (1) flow injection mode, in which there is no analyte separation, and (2) LC mode, in which mixtures of analytes are separated chromatographically to allow isotopic analysis of individual components. To date this interface in both configurations has been used for the analysis of several classes of small molecules which include lipids, vitamins, and carbohydrates sampled from organic solvent $[7,8]$. We have not demonstrated the applicability of this technique to analysis of the carbon isotope ratios in the aqueous phase or to biolog- 
ical macromolecules, both of which pose special challenges to mass spectrometry-based techniques. The goal of this report is to demonstrate the ability of the moving transport LCC-IRMS interface to detect differences in carbon isotope ratios of biological macromolecules dissolved in the aqueous phase. The samples analyzed are commercially available purified proteins, albumins and albumens, derived from 18 species. The possible significance of observed differences in isotope ratio are discussed.

\section{Experimental}

\section{Protein Samples}

Eighteen purified serum albumin samples derived from 18 different species and 2 purified egg albumen samples were purchased from the Sigma Chemical Company (St. Louis, MO). The samples were fraction $\mathrm{V}$ powders prepared by using a modified Cohn purification, in which the albumin is isolated by using cold ethanol with a $\mathrm{pH}$-specific low temperature precipitation [9], followed by $\mathrm{pH}$ adjustment and drying. Stock solutions of each sample albumin were mate by resuspension of the powder in high-performance liquid chromatography (HPLC) grade water (Fisher Scientific, Fair Lawn, NJ). Isotopic analyses of all samples were performed by using flow injection LCC-IRMS. This analysis mode provides no means for removal of contaminants, so their presence must be sufficiently low that they do not contribute significantly to the measured isotope ratios. For an analytical precision of LCC-IRMS of about $\operatorname{SD}\left(\delta^{1.3} \mathrm{C}\right)=0.5 \%$, contaminants should not alter the isotope ratio by more than this amount. The purity needed to ensure that this specification is met can be estimated with the following assumptions. (1) The natural abundance range for carbon extends from approximately $\delta^{13} \mathrm{C}=-5$ to $-40 \%$. In the worst case the component of interest would, for example, have an isotope ratio at one extreme $(-40 \%)$ while the contaminant is at the other extreme $(-5 \%)$. (2) Assuming the species of interest and the contaminant have similar molar carbon content, the net isotope ratio is a weighted sum of the isotope ratios of the respective components and can he estimated by using a modified version of a formula used to calculate the isotopic contribution of a derivatization [10]:

$$
F^{\text {an }} \times \delta^{13} \mathrm{C}_{\mathrm{P} \mathrm{DB}}^{\mathrm{ann}}+F^{\mathrm{con}} \times \delta^{13} \mathrm{C}_{\mathrm{P} P \mathrm{~PB}}^{\mathrm{con}}=\delta^{1.3} \mathrm{C}_{\mathrm{P} \mathrm{DB}}^{\mathrm{net}}
$$

where $F^{x}$ is the fraction of total carbon, an, con, and net reter to the analyte, contaminant, and overall sample, respectively, and $\delta^{13} \mathrm{C}_{\mathrm{PDB}}^{x}$ is given by the usual formula

$$
\delta{ }^{13} \mathrm{C}_{\mathrm{PDOB}}=\left(\frac{R_{\mathrm{SPL}}-R_{\mathrm{PDA}}}{R_{P D B}}\right) \times 1000
$$

where $\left.R_{x}=\left[{ }^{13} \mathrm{C}\right] /{ }^{12} \mathrm{C}\right]$ and $R_{\mathrm{PDB}}=0.0112372$, is the ratio for the international standard PeeDee Belemnite (PDB) [11]. Solving eq. 3 for $F^{\mathrm{con}}$, substituting $F^{\text {an }}=1$ $-F^{\mathrm{con}}$, and rearranging, we have

$$
F^{\mathrm{con}}=\left(\frac{\delta^{13} \mathrm{C}^{\text {net }}-\delta^{13} \mathrm{C}^{\mathrm{an}}}{\delta^{13} \mathrm{C}^{\mathrm{con}}}\right)\left(1-\frac{\delta^{13} \mathrm{C}^{\mathrm{an}}}{\delta^{13} \mathrm{C}^{\mathrm{con}}}\right)^{-1}
$$

Substituting $\delta^{13} \mathrm{C}^{\mathrm{an}}=-5 \% 0, \delta^{13} \mathrm{C}^{\mathrm{con}}=-40 \%$, and $\delta^{13} \mathrm{C}^{\text {net }}=-5-(-0.5)=-5.5 \%$, we find that the maximum acceptable contamination level is about $1.4 \%$.

\section{Purity Analysis}

Capillary zone electrophoresis (CZE) separation of each albumin sample was performed by using an Applied Biosystems (Foster City, Ca) CZE 270 system, operated by using a voltage drop of $\sim 350 \mathrm{~V} \mathrm{~cm}^{-1}$ across a $72-\mathrm{cm}$ column held at $30^{\circ} \mathrm{C}$. The separation was followed by monitoring the absorbance at $200 \mathrm{~nm}$ and was performed at both $\mathrm{pH} 2.5$ and 11.0.

HPLC separations were performed on a SSI HPLC (Scientific Systems, Inc., State College, PA) equipped with a $10-\mu \mathrm{L}$ injection loop. Injections of the albumin samples $(20 \mathrm{mg})$ were made onto a Synchrom ${ }^{\mathrm{TM}}$ Inc. (Linden, IN) Sychropak GPC 100 column $(25 \mathrm{~cm} \times 4.1$ $\mathrm{mm}$ i.d.) and were eluted isocratically with $0.1-\mathrm{M}$ $\mathrm{KH}_{2} \mathrm{PO}_{4}, \mathrm{pH} 7.0$, supplied at $1 \mathrm{~mL} \mathrm{~min}^{-1}$, with detection at $280 \mathrm{~nm}$.

\section{Dual Inlet Isotopic Calibration}

All of the protein samples were analyzed for ${ }^{13} \mathrm{C} /{ }^{12} \mathrm{C}$ ratio by loading $1 \mathrm{mg}$ of sample into $6-\mathrm{mm} \mathrm{Vycor}^{\mathrm{TM}}$ tubes that contained $200 \mathrm{mg}$ of $\mathrm{CuO}$ and $25 \mathrm{mg}$ of $\mathrm{Ag}$ flake, evacuating, baking at $850{ }^{\circ} \mathrm{C}$ for $3 \mathrm{~h}$, and analyzing by conventional dual inlet IRMS as previously described. All calibrations can be traced to National Institutes of Standards and Technology (NIST) supplied reference material RM8541 (USGS 24, graphite) with defined ${ }^{13} \mathrm{C} /{ }^{12} \mathrm{C}$ ratio. Signal traces for the three measurement channels were processed by vendor supplied software for peak definition and isotope ratio calculation.

\section{HPLC-Flow-Injection Conditions}

A SSI injector with a 10-mL injection loop and a HPLC pump was used as the liquid source for flow-injection analysis. Replicate $2.5-\mu \mathrm{g}$ injections of each aqueous albumin sample were made into HPLC grade water (Fisher, Pittsburgh, P'A) at a flow rate of $0.5 \mathrm{~mL}$ min ${ }^{1}$. Injections of similar quantities of an isotopically calibrated internal standard albumin also were made within each series of runs. 


\section{LCC-IRMS Interface Operating Conditions}

The LCC-IRMS interface used in this work was similar in design to the interface presented previously [8]. It consists of a fully softened bright annealed stainless steel wire (diameter $0.003 \mathrm{in}$.) moving with a velocity of $12.5 \mathrm{~cm} \mathrm{~s}^{-1}$ through a $10-\mathrm{cm}$ cleaning furnace maintained at $900{ }^{\circ} \mathrm{C}$. A parallel flow of $\mathrm{O}_{2}\left(15 \mathrm{~mL} \mathrm{~min}^{-1}\right)$ purged the furnace to efficiently remove all organic contaminants and to produce an oxide coating on the wire. The clean wire then looped around a transfer wheel and passed into an enclosed coating block. The analyte solution passed through a heated $\left(150{ }^{\circ} \mathrm{C}\right)$ pneumatic nozzle and was converted into an aerosol. The nozzle was positioned $10 \mathrm{~mm}$ above the wire at a $45^{\circ}$ incident angle and coated the wire. The coated wire then passed through a 5-cm drying oven, where solvent was evaporated reproducibly at $190{ }^{\circ} \mathrm{C}$ with $100-\mathrm{mL} \mathrm{m^{-1 }}{ }^{-1}$ counterflowing $\mathrm{He}$, and then passed into the combustion furnace.

The combustion furnace $(15 \mathrm{~cm} \times 2 \mathrm{~mm})$ was loaded with two $8-\mathrm{cm}$ lengths of copper wire (diameter 0.012 in.) that were oxidized to $\mathrm{CuO}$, and two $8-\mathrm{cm}$ lengths of platinum wire (diameter $0.003 \mathrm{in}$.). During operation, the furnace was maintained at $900{ }^{\circ} \mathrm{C}$ to promote the $\mathrm{CuO} / \mathrm{Cu}+\mathrm{O}_{2}$ equilibrium that supplies the $\mathrm{O}_{2}$ required for combustion. The dried analyte was converted quantitatively to $\mathrm{CO}_{2}$ and $\mathrm{H}_{2} \mathrm{O}$, which were swept by the leading He carrier gas stream $(30 \mathrm{~mL}$ $\mathrm{min}^{-1}$ ) to the IRMS sampling capillary at the end of the furnace. The second, lagging, He stream flowed at a rate of about $20 \mathrm{~mL} \mathrm{~min}^{-1}$ to minimize admission of atmosphere to the IRMS.

After the analyte stream entered the IRMS sampling capillary, it was dried by passage through a 5 -cm Nafion $^{\text {TM }}$ water trap and transferred via a $5-\mathrm{m}$ fused silica capillary (i.d. $=100 \mathrm{~mm}$ ) to the ion source inlct of a Finnigan-MAT (San Jose, CA) 252 IRMS system. The IRMS was operated with a source pressure of $6 \times 10^{-7}$ torr and an accelerating potential of $8 \mathrm{kV}$. The ionization efficiency at the time of the analyses was 1800 neutrals per ion.

\section{Isotopic Calibration}

In previous studies, it was observed that statistically different isotope ratios are obtained when raw area ratios calculated by the Finnigan ISODAT data system are calibrated against external standard $\mathrm{CO}_{2}$ pulses admitted directly to the ion source from one of the dual variable volume inlets versus those calibrated against internal standards. Peaks calibrated against $\mathrm{CO}_{2}$ pulses are generally offset by a constant compared to known values, whereas calibrations against internal standards are accurate to within $\delta^{13} \mathrm{C}<$ $\pm 0.5 \%$ for flow injection. Therefore in the present work, all isotope ratios were calculated by using an isotopically calibrated internal standard included with each series of LCC-IRMS analyses.

\section{Results and Discussion}

\section{Albumin Purity}

The purity of the samples assessed by using HPLC and $\mathrm{CZE}$ separation at $\mathrm{pH} 2.5$ and 11.0 revealed little contamination. All of the albumins were $>99 \%$ pure with the exception of the human albumin, which was $98.6 \%$ pure. $\mathrm{CZE}$ at $\mathrm{pH} 2.5$ indicated a purity of $>99 \%$ for all the samples with the exception of the rat and chicken albumin at 95.6 and $97.9 \%$, respectively. $\mathrm{CZE}$ analysis at $\mathrm{pH} 11.0$ resolved more minor contaminants and gave a mean purity of $96.7 \%$, although several samples had significant contaminant levels (human, 93.3\%; pigeon, 92.9\%; chicken, $92.7 \%$ ). These results suggest caution is necessary for the interpretation of isotope ratio results for samples of low purity, because in the worst case their measured isotope ratio may be as much as $2 \%$ from the true isotope ratio. However, the results that follow show that the measured isotope ratios are not at the extremes of the natural abundance range and therefore the worst case scenario should not strictly apply.

\section{Isotope Ratio Analysis}

The results of isotope ratio analysis by both dual inlet analysis and on-line LCC-IRMS are summarized in Table 1. Precision of the analyses by dual inlet averaged $\operatorname{SD}\left(\delta^{13} \mathrm{C}\right)=0.2 \%$ for replicates, whereas that for on-line LCC-IRMS averaged $\operatorname{SD}\left(\delta^{13} \mathrm{C}\right)=0.45 \%$. No outliers were excluded from this data set.

Accuracy of the LCC-IRMS instrument was measured by comparing the on-line results with those obtained by the dual inlet (DI) method of analysis as shown in Figure 1. Least squares fitting shows that the intercept is not statistically different from 0 and the slope is not different from 1 at the $95 \%$ confidence level, and the correlation coefficient is $r^{2}>0.97$. The mean of the absolute value of the difference between dual inlet analysis and the corresponding LCC-IRMS analysis was $0.45 \%$, which can be taken to represent the average accuracy for these analyses. More importantly, the sum of the deviations of LCC-IRMS values from their respective DI reference values for all 20 samples is $\delta^{13} \mathrm{C}<0.08 \%$. A paired $t$-test shows the difference between corresponding measurements is not significant $(p=0.5)$. In summary, there was no statistically detectable bias with the LCC-IRMS method.

\section{Interspecies Variation in Albumin Isotope Ratio}

It long has been known that the carbon isotope ratios of animal bodies are distributed within the range found for photosynthetic organisms [12-14] and that two principal factors govern the net isotope ratio in a particular individual. First, animals generally exhibit isotope ratios that are approximately $\delta^{13} \mathrm{C}_{\mathrm{PDB}}=1-3 \% \mathrm{C}$ greater than their diet [15-17], as a direct result of the 
Table 1. Summary of isotope ratio analyses obtained by dual inlet and LCC-IRMS ${ }^{a}$

\begin{tabular}{|c|c|c|c|c|}
\hline & & Dual inlet & LCC-IRMS & $\begin{array}{c}\text { LCC-IRMS } \\
\text { precision (SD) }\end{array}$ \\
\hline \multirow[t]{5}{*}{ Avian } & Pigeon (Pn) & -16.66 & -16.13 & 0.79 \\
\hline & Turkey $(T)$ & -16.47 & -16.01 & 0.21 \\
\hline & $\begin{array}{l}\text { Turkey Egg } \\
\text { Albumen (Et) }\end{array}$ & -17.80 & -18.02 & 0.47 \\
\hline & Chicken (Cn) & -16.28 & -16.42 & 0.54 \\
\hline & $\begin{array}{l}\text { Chicken Egg } \\
\text { Albumen (Ec) }\end{array}$ & -17.13 & -17.32 & 0.52 \\
\hline \multirow[t]{3}{*}{ Primates } & Baboon (B) & -18.06 & -17.56 & 0.45 \\
\hline & Human $(\mathrm{H})$ & -18.18 & -18.17 & 0.69 \\
\hline & Rhesus (Rh) & -19.32 & -19.20 & 0.50 \\
\hline \multirow[t]{5}{*}{ Rodents } & Mouse (M) & -18.70 & -18.23 & 0.17 \\
\hline & Rat $\langle R t\rangle$ & -18.91 & -18.85 & 0.55 \\
\hline & Hamster $(H)$ & -19.35 & -20.64 & 0.60 \\
\hline & Guinea Pig (GP) & -21.10 & -21.56 & 0.43 \\
\hline & Rabbit (Rbt) & -22.30 & -22.60 & 0.13 \\
\hline \multirow[t]{4}{*}{ Ruminants } & Sheep (S) & -16.67 & -16.25 & 0.16 \\
\hline & Goat $(G)$ & -19.36 & -19.99 & 0.33 \\
\hline & Horse $(\mathrm{H})$ & -21.28 & -21.04 & 0.61 \\
\hline & Donkey (Dy) & -20.91 & -21.77 & 0.50 \\
\hline \multirow[t]{3}{*}{ Other } & Pig (Pg) & -16.36 & -16.42 & 0.56 \\
\hline & $\operatorname{Dog}(D g)$ & -17.10 & -16.98 & 0.22 \\
\hline & Cat $(\mathrm{Ct})$ & -17.50 & -18.16 & 0.76 \\
\hline
\end{tabular}

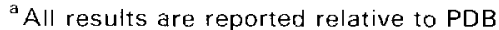

selective respiration of ${ }^{12} \mathrm{CO}_{2}$ over ${ }^{1.3} \mathrm{CO}_{2}$, which results in an accumulation of ${ }^{13^{2}} \mathrm{C}$. The other major determinant is the initial carbon isotope ratio of the primary carbon source in a particular food chain, which is determined by photosynthetic pathway $[18,19]$. Plants

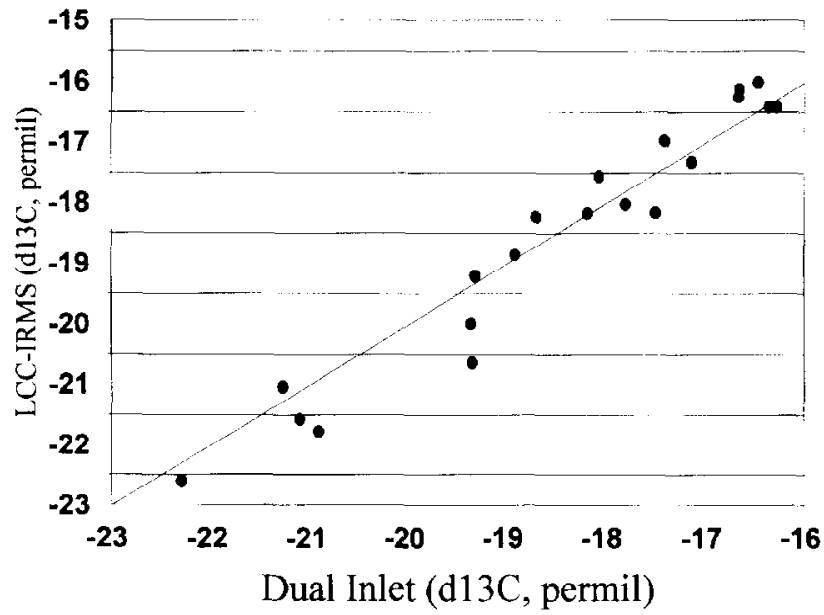

Figure 1. Comparison of isotope ratios obtained by dual inlet and on-line LCC-RMS. The theoretical line of identity $\left(\delta^{13} \mathrm{C}^{\mathrm{D})}=\right.$ $\delta^{13} \mathrm{C}^{(\mathrm{l})}$ ) is overlaid on the plot. A linear least squares fit yields $y=2.007( \pm 2.364)+1.113( \pm 0.127) x,( \pm 95 \%$ confidence limits $)$ and $r^{2}>0.97$. that use the $\mathrm{C} 4$ pathway have carbon isotope ratios that average $-13.6 \%$, whereas $\mathrm{C} 3$ plants have average carbon isotope ratios of $-27.8 \%$ [ $[20,21]$. Primary or secondary consumers then take on the $\mathrm{C}$ isotope ratio of the source, plus metabolic enrichment. These facts are often exploited for paleodietary reconstruction via collagen isotope ratio analysis and also have been used to analyze the structures of various food webs [22-24].

The primary goal of this work was to demonstrate the applicability of LCC-IRMS to the analysis of protein molecules dissolved in an aqueous medium. Although the proteins were prepared commercially without evaluation of isotopic fractionation, it is likely that fractionation during purification is minimal because of the very high molecular weights, and such fractionation should be constant because the procedures are identical for each protein. Several general observations with regard to the distribution of isotopes in these species and the likely composition of their diets can be made.

In Figure 2 the albumin isotope ratios obtained by LCC-IRMS analysis are plotted in order of ${ }^{1.3} \mathrm{C}$ content; error bars denote standard deviations. This plot shows that there is a continuous distribution of isotope ratios over a range of approximately $7 \%$. Interestingly, species within classes exhibit similar ${ }^{1.3} \mathrm{C}$ content. For 


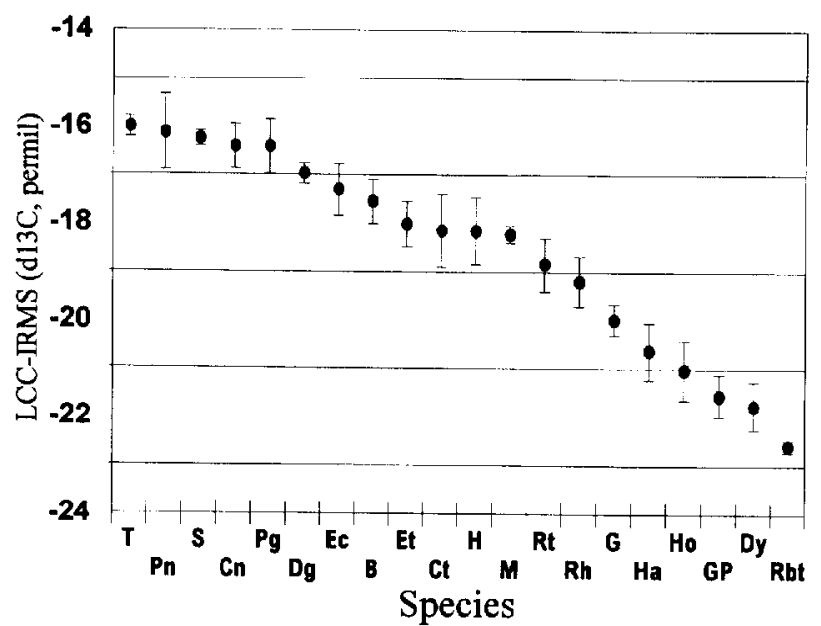

Figure 2. $\quad \delta^{13} \mathrm{C}$ of albumin in each of the 20 samples analyzed by on-line LCC-IRMS, ordered highest to lowest ${ }^{13} \mathrm{C}$ content to illustrate the range over which isotope ratios are observed. Abbreviations correspond to labels in Table 1. Error bars reflect standard deviations.

example, the avian species generally have the highest isotope ratios, about -16 to $-17 \%$, which reflects either corn (C4) consumption or the compounded metabolic ${ }^{13} \mathrm{C}$ concentration of carnivores. The herbivorous-omnivorous ruminants and rodents lie at the other end of the spectrum with isotope ratios that range from -18 to $-22 \%$. Interestingly, the isotope ratios for both chicken and turkey egg albumens are lower than the respective adults by approximately $1 \%$. The cause for this difference is unclear, but it may be a reflection of the lower metabolic activity of the egg protein compared to plasma albumin of the adults.

Comparisons of the isotope ratios measured for a wide variety of species correspond remarkably well with those of other investigators. For example, Lyon and Baxter [25] analyzed the ${ }^{13} \mathrm{C}$ content in various tissues and body fluids in humans. The blood, which is the most suitable compartment for comparison with serum albumin, exhibited an isotope ratio of $-18.22 \%$, which is within the analytical precision of our measurement of $-18.17 \%$. Jones et al. [26] investigated the effect of a diet high in grass (C4) or legumes (C3) on sheep tissue isotope ratios. They observed that the fecal isotope ratio shifted from a range of -23.5 to $-26.6 \%$ for the legume diet to about $-13.1 \%$ for the grass diet. Comparison with our sheep albumin results suggests that the source of our albumin was consumption of a C4-rich diet. Ambrose et al. [27] analyzed the isotope ratios for bone collagen derived trom blue monkeys and anubis baboons (both of which are classified as "browsers") and found isotope ratios of -19.4 and $-17.3 \%$, respectively. Our analyses of rhesus monkey and baboon albumin again yielded quite similar isotope ratios of -19.20 and $-17.56 \%$, respectively [27]. Finally Schoeninger and DeNiro investigated bone collagen isotope ratios for rabbits $(-22.0 \%)$, horses $(-21.2 \%)$, domestic turkeys $(-12.6 \%)$, and wood rats $(-16.9 \%)$, along with many other species. LCC-IRMS analysis of the corresponding albumins produced similar results, with rabbit at $-22.6 \%$ and horse at $-21.28 \%$, and with somewhat lower correspondence for turkey $(-16.47 \% 0)$ and rat $(-18.90 \% 0)$. Overall, these results suggest that the isotope ratios measured in the present work are free from extensive fractionation and appear to reflect average body isotope ratios.

In summary, the LCC-IRMS system determined carbon isotope ratios of purified albumin directly from the aqucous phase with high precision and accuracy, which further extends the range of molecules that are amenable to analysis with this instrument. Time for each analysis was approximately $300 \mathrm{~s}$, compared to approximately $20 \mathrm{~min}$ for $\mathrm{DI}$ analysis. Although the albumins were not isolated in our hands, extensive isotopic fractionation does not appear to have occurred as evidenced by the correspondence of these results with comparable published data.

\section{Acknowledgments}

This work was supported by NIH grant GM49209. RJC acknowledges predoctoral support from NIH training grant DK07158.

\section{References}

1. Ehleringer, J. R.; Rundel, P. W. Stable Isotopes: History, Units, and Instrumentation. In Stable Isotopes in Ecological Research; Rundel, P. W.; Lhleringer, J. R.; Nagy, K. A., Eds.; SpringerVerlag: New York, 1988.

2. Nier, A. O. Rev. Sci. Instrum. 1940, 11, 212-216.

3. Guilluy, R.; Billion-Rey, F.; Pachiaudi, C.; Normand, S.; Roud, J. P.; Jumeau, E. J.; Brazier, J. L. Anal. Chim. Acta 1992, 259, 193-202.

4. Hilkert, A. W.; Brand, W. A. Second World Conference on Stable Isotope and Nutrition Metabolism Research; 1994, L14.

5. Sano, M.; Yotsui, Y.; Abe, H.; Sasaki, S. Biomed. Mass Spectrom. 1976, 3, 1-3.

6. Matthews, D. E.; Hayes, J. M. Anal. Chem. 1978, 50, 1465-1473.

7. Caimi, R. J.; Brenna, J. T. Anal. Chem. 1993, 23, 3497-3500.

8. Caimi, R. J.; Brenna, J. T. J. Mass Spertrom. 1995, 30, 466-472.

9. Cohn, E. J.; Strong, L. E.; Hughes, W. L., Jr.; Mulford, D. J.; Ashworth, J. N.; Melin, M.; Taylor, H. L. I. Am. Chem. Soc. 1946, 68, 459-475.

10. Goodman, K. J.; Brenna, J. T. Anal. Chem. 1992, 64, 1088-1095.

11. Craig, H. Geochim. Cosmochim. Acta 1957, 12, 133-149.

12. Minson, D. J.; Ludlow, M. M.; Troughton, J. H. Nature 1975, 256,602 .

13. Haines, E. B. Limnol. Oceanogr. 1976, 21, 880.

14. Fry, B.; Joern, A.; Parker, P. L. Ecology 1978, 59, 498-506.

15. DeNiro, M. J.; Epstein, S. Geochim. Cosmochim. Acta 1978, 42, 495-506.

16. Mosora, F.; Lacroix, M.; Duchesne, J. C. R. Acad. Sci. Paris Ser. D 1971, 273, 1752-1753.

17. McConnaughey, T.; McRoy, C. P. Marine Biol. 1979, 53, 257-262.

18. Park, R.; Epstein, S. Geochim. Cosmochim. Acta 1960, 21, 110-126.

19. Christeller, J. T.; Laing, W. A.; Troughton, J. H. Plant Physiol. 1976, 57, 580-582.

20. Smith, B. N.; Epstein, S. Plant Physiol. 1971, 47, 380-384. 
21. Lerman, J. C. In Environmental and Biological Control of Photosynthesis; Marcelle, R., Ed.; Junk: The Hague, 1975, pp. 323-335.

22. Teeri, J. A.; Schoeller, D. A. Oecologia 1979, 39, 197-200.

23. Schoeninger, M. J.; DeNiro, M. J. Geochim. Cosmochim. Acta $1984,48,625-639$.
24. Tauber, H. Nature 1981, 292, 332-333.

25. Lyon, T. D. B.; Baxter, M. S. Nature 1978, 273, 750-751.

26. Jones, R. J; Ludlow, M. M.; Troughton, J. H.; Blunt, C. G. J. Agr. Sci. 1979, 92, 91-100.

27. Ambrose, S. H., DeNiro, M. J. Oecologia 1986, 69, 395-406. 